\title{
Acute effects of mustard, horseradish, black pepper and ginger on energy expenditure, appetite, ad libitum energy intake and energy balance in human subjects
}

\author{
N. T. Gregersen ${ }^{1 *}$, A. Belza ${ }^{1}$, M. G. Jensen ${ }^{1}$, C. Ritz ${ }^{2}$, C. Bitz ${ }^{1}$, O. Hels ${ }^{3}$, E. Frandsen ${ }^{4}$, D. J. Mela \\ and A. Astrup ${ }^{1}$ \\ ${ }^{1}$ Department of Human Nutrition, Faculty of Life Sciences, University of Copenhagen, Rolighedsvej 30, DK-1958 \\ Frederiksberg C, Denmark \\ ${ }^{2}$ Department of Basic Sciences and Environment, Faculty of Life Sciences, University of Copenhagen, Frederiksberg, \\ Denmark \\ ${ }^{3}$ StatistiConsult, Ølstykke, Denmark \\ ${ }^{4}$ Department of Clinical Physiology and Nuclear Medicine, Glostrup University Hospital, Glostrup, Denmark \\ ${ }^{5}$ Unilever RED Vlaardingen, Vlaardingen, The Netherlands
}

(Submitted 11 August 2011 - Final revision received 24 February 2012 - Accepted 24 February 2012 - First published online 5 July 2012)

\begin{abstract}
Chilli peppers have been shown to enhance diet-induced thermogenesis (DIT) and reduce energy intake (EI) in some studies, but there are few data on other pungent spices. The primary aim of the present study was to test the acute effects of black pepper (pepper), ginger, horseradish and mustard in a meal on $4 \mathrm{~h}$ postprandial DIT. The secondary aim was to examine the effects on subjective appetite measures, ad libitum EI and energy balance. In a five-way placebo-controlled, single-blind, cross-over trial, twenty-two young (age 24.9 (sD 4.6) years), normal-weight (BMI $21.8(\mathrm{SD} 2 \cdot 1) \mathrm{kg} / \mathrm{m}^{2}$ ) males were randomly assigned to receive a brunch meal with either pepper $(1.3 \mathrm{~g})$, ginger $(20 \mathrm{~g})$, horseradish $(8.3 \mathrm{~g})$, mustard $(21 \mathrm{~g})$ or no spices (placebo). The amounts of spices were chosen from pre-testing to make the meal spicy but palatable. No significant treatment effects were observed on DIT, but mustard produced DIT, which tended to be larger than that of placebo $(14 \%, 59(\mathrm{SE} 3) v .52(\mathrm{SE} 2) \mathrm{kJ} / \mathrm{h}$, respectively, $P=0 \cdot 08)$. No other spice induced thermogenic effects approaching statistical significance. Subjective measures of appetite $(P>0.85)$, ad libitum EI $(P=0.63)$ and energy balance $(P=0.67)$ also did not differ between the treatments. Finally, horseradish decreased heart rate $(P=0.048)$ and increased diastolic blood pressure ( $P=0.049)$ compared with placebo. In conclusion, no reliable treatment effects on appetite, EI or energy balance were observed, although mustard tended to be thermogenic at this dose. Further studies should explore the possible strength and mechanisms of the potential thermogenic effect of mustard actives, and potential enhancement by, for example, combinations with other food components.
\end{abstract}

Key words: Diet-induced thermogenesis: Bioactive components: Randomised studies: Placebo-controlled studies

The combination of the worldwide obesity epidemic ${ }^{(1)}$ and the fact that long-term weight maintenance following a previous weight loss is often unsuccessful ${ }^{(2)}$ poses a major threat to global health. Thus, approaches for preventing a positive energy balance and thereby weight gain are warranted. Bioactive components from specific pungent spices and teas have in some studies been capable of helping to offset a positive energy balance by increasing thermogenesis ${ }^{(3-6)}$ and decreasing energy intake $(\mathrm{EI})^{(7)}$.

One of the best studied of the pungent spices is chilli peppers ${ }^{(3,4,8-10)}$. Studies have shown that the pungent component, capsaicin, in chilli peppers can increase thermogenesis in both animals $^{(11,12)}$ and human subjects ${ }^{(3,4)}$, although the evidence is not consistent ${ }^{(4,13,14)}$. According to the evidence from rat studies, it seems that this capsaicin-induced increase in thermogenesis is due to the stimulation of catecholamine secretion from the adrenal medulla primarily through the sympathetic activation of the central nervous system ${ }^{(15,16)}$. This effect seems to be mediated through $\beta$-adrenergic stimulation, since the effect on thermogenesis disappears after administration with $\beta$-blocking agents such as propranolol in both animals ${ }^{(17)}$ and human subjects ${ }^{(4)}$. The transient receptor potential

Abbreviations: AITC, allyl isothiocyanate; BP, blood pressure; DIT, diet-induced thermogenesis; E\%, percentage of energy; EE, energy expenditure; EI, energy intake; HR, heart rate; RQ, respiratory quotient; SNS, sympathetic nervous system; TRPV1, transient receptor potential vanilloid 1; VAS, visual analogue scale.

*Corresponding author: N. T. Gregersen, fax +45 35332483, email nikolajturegregersen@hotmail.com 
vanilloid 1 (TRPV1), which is a nociceptor, has a high affinity for capsaicin $^{(18)}$, and thus plays a central role in eliciting the effects of capsaicin on the sympathetic nervous system (SNS). In addition, it has been suggested that capsaicin may affect appetite and $\mathrm{EI}^{(10)}$.

Despite the evidence of the possible effects of chilli on energy metabolism, the effects of other pungent spices are not well studied. However, infusion of piperine, the pungent component in black pepper, increased catecholamine secretion in anaesthetised rats and thereby stimulated thermogenesis through the $\mathrm{SNS}^{(15)}$. Likewise, gingerols and shogaols, the major bioactive components in ginger (Zingiber officinale), have been shown to activate the TRPV1 receptor by increasing adrenaline secretion in rats ${ }^{(19)}$. However, in human subjects no increase in metabolic rate was seen when ginger was added to a meal compared with when the meal was served alone ${ }^{(20)}$. Mustard (containing the bioactive component allyl isothiocyanate (AITC)) has also been reported to be capable of increasing the metabolic rate in human subjects ${ }^{(21)}$, but in that study, the subjects were given mustard in combination with chilli pepper, which makes it impossible to isolate the effect of mustard alone.

Apart from the rather sparse in vivo evidence for the effects of these other spices on energy metabolism, the plausibility of the concept is supported by in vitro data. For example, AITC, gingerols, shogaols and piperine have been shown to bind to the TRPV1 receptors, like capsaicin, which suggests that these components may potentially affect energy expenditure (EE), appetite and EI in a similar way as capsaicin ${ }^{(19,22,23)}$.

Taken together, since the evidence for many of these pungent spices on energy metabolism and appetite/EI is rather limited and much of this is based on animal studies, well-designed human intervention studies are needed in order to clarify which pungent spices might affect the components of energy balance in humans, within the range of palatability. Thus, the primary objective of the present study was to examine whether ginger, horseradish, mustard and black pepper added (in their natural form) to a meal have any acute effects on diet-induced thermogenesis (DIT). As secondary endpoints, we analysed subjective appetite sensations, ad libitum EI, substrate oxidation, blood pressure (BP) and heart rate (HR).

Post hoc analyses of energy balance are also reported.

We hypothesised that the spices would increase DIT and satiety, and potentially also reduce the ad libitum EI. Furthermore, based on the expected activation of the SNS, we hypothesised that the spicy meals would increase BP and HR. Other blood parameters were included only as explorative endpoints with no associated hypotheses.

Importantly, the amounts of spices were chosen to make the meal spicy but palatable.

\section{Methods}

\section{Subjects}

A total of twenty-five healthy, normal-weight male subjects recruited from universities in Copenhagen and Internet advertisements were included in the study. Inclusion criteria were males with $\mathrm{BMI}<25 \mathrm{~kg} / \mathrm{m}^{2}$, BP $<140 / 90 \mathrm{mmHg}$ and normal electrocardiogram. Furthermore, the subjects had to like spicy food in general and the four spices under investigation in particular. Exclusion criteria were smoking and a high level of physical activity (more than $10 \mathrm{~h}$ exercise/week). Men were chosen over women in order to avoid having to control for the menstrual cycle. The subject characteristics for the included subjects are shown in Table 1 . For $24 \mathrm{~h}$ before each test day, the subjects were asked to avoid intake of alcohol, hot spices and caffeine-containing foods including coffee, tea, cola and chocolate. In addition, the subjects were asked to refrain from strenuous physical activity for $48 \mathrm{~h}$ before each test day. All the subjects signed a written informed consent before participating in the study, which was in accordance with the Declaration of Helsinki and approved by the Municipal Ethical Committee of Copenhagen and Frederiksberg ((KF) 01-188/00). The study was registered at ClinicalTrials.gov (ClinicalTrials.gov identifies: NCT 00611156).

\section{Experimental design}

The study was a five-way crossover, randomised, single-blind (researcher staff were blinded), placebo-controlled design. Subjects were randomised using blockwise Latin square randomisation (for blocks of five subjects).

The specific spices (ginger, horseradish, mustard, black pepper and placebo) were administered as fresh spices added to a test brunch meal. Each test day was separated by a $>3$-week washout period to allow subjects to regenerate the blood drawn during the previous test day.

\section{Respiratory measurements}

The subjects' RMR and respiratory quotient (RQ) were measured by indirect calorimetry using a ventilated hood system (Oxycon Champion; Meijnhardt BV). RMR, RQ and substrate oxidation were calculated using the formulas by Elia \& Livesey ${ }^{(24)}$. The precision of the ventilated hood system was validated on a weekly basis by an alcohol burning test; CV was $1.5 \%$.

On each test day, subjects arrived fasting at the Department of Human Nutrition in Frederiksberg, Copenhagen at 07.30 hours. After voiding (emptying of the bladder), the subjects were weighed to the nearest $0.05 \mathrm{~kg}$ on a decimal scale (Lindeltronic 8000) and had their body composition (fat-free mass and fat mass) determined by bioelectrical impedance (Animeter;

Table 1. Subject characteristics at baseline (Mean values, standard deviations and ranges, $n$ 22)

\begin{tabular}{lrrc}
\hline Characteristics & Mean & SD & Range \\
\hline Age (years) & 24.9 & 4.6 & $19-37$ \\
Weight $(\mathrm{kg})$ & 73.4 & 10.3 & $60.2-97.9$ \\
Height $(\mathrm{cm})$ & 183.5 & 7.8 & $166-198$ \\
BMl $\left(\mathrm{kg} / \mathrm{m}^{2}\right)$ & 21.8 & 2.1 & $18.0-25.0$ \\
FM $(\mathrm{kg})^{\star}$ & 11.0 & 5.0 & $2.5-22.1$ \\
FFM $(\mathrm{kg})^{\star}$ & 62.4 & 6.2 & $54.2-75.8$ \\
\hline
\end{tabular}

FM, fat mass; FFM, fat-free mass. ${ }^{*}$ Calculated from bioelectrical impedance. 
Unitech). At 08.00 hours, a venflon catheter was inserted into the right arm of the subjects and $2 \mathrm{ml}$ were drawn for the measurement of $\mathrm{Hb}$ concentration. A three-way stopcock was attached to the venflon catheter to allow repeated blood sampling throughout the test day. Then, the subjects rested in a supine position for $30 \mathrm{~min}$, where respiratory measurements $(2 \times 25 \mathrm{~min})$ were conducted between 08.30 and 09.30 hours after baseline. The test brunch meal was served at 09.30 hours and followed by $4 \mathrm{~h}$ (10.00-14.00 hours) of postprandial respiratory measurements $(8 \times 25 \mathrm{~min})$.

HR and systolic and diastolic BP were measured every half hour between 09.00 and 14.00 hours using a digital blood pressure monitor (Model UA-787; A\&D Medical). Blood samples were also drawn every half hour between 09.30 and 14.00 hours (except at 13.30 hours) for analyses of NEFA, TAG, total cholesterol, HDL, glucose and insulin. LDL levels were estimated using the formula by Friedewald et al. ${ }^{(25)}$. At 14.00 hours, the venflon catheter was removed and the final collection of urine was made. An ad libitum lunch was served at 14.15 hours and after finishing the lunch, the subjects were allowed to leave the department.

\section{Meals}

All meals were prepared by a specifically educated kitchen staff using standardised recipes.

The standardisation meal consisted of pasta with meat sauce, a multifruit juice and crackers, and was to be eaten before 20.00 hours the evening before the test day. This meal contained $4.5 \mathrm{MJ}$ and had a macronutrient composition of $60 \%$ of energy (E\%) carbohydrate, $22 \mathrm{E} \%$ fat and $18 \mathrm{E} \%$ protein.

The test brunch meal was served at 09.30 hours and consisted of bread, ham, butter, raspberry jam, stewed apples, scrambled eggs, shredded beetroot, $250 \mathrm{ml}$ multifruit juice and $200 \mathrm{ml}$ water. In addition to the above-mentioned foods, the test meal contained either (1) $20 \mathrm{~g}$ fine-chopped ginger (imported from Thailand by A\&C Catering) in the stewed apples, (2) $8.3 \mathrm{~g}$ shredded horseradish (from Denmark, A\&C Catering) in the shredded beetroot, (3) $21 \mathrm{~g}$ Dijon mustard (Maille ${ }^{\circledR}$ Dijon Originale) (corresponding to $14 \mathrm{~g} \mathrm{DM}$ ) in the shredded beetroot, (4) $1.3 \mathrm{~g}$ black pepper (imported from Vietnam by KRYTA A/S, INCO) divided between the shredded beetroot and the scrambled eggs or (5) no added spices (placebo). The amounts of spices were chosen from pre-testing to make the meal spicy but palatable. The five different versions of the test meal were aimed at being isoenergetic, but varied slightly due to minor differences in preparation (Table 2). This meal was to be eaten within $20 \mathrm{~min}$.
The ad libitum lunch consisted of pizza with tomato sauce, ham and cheese, and was served with $500 \mathrm{ml}$ water. The amount of water consumed by the subject at the first visit (maximum $500 \mathrm{ml}$ ) was reproduced at the subsequent test days. The lunch had an energy content of $1062 \mathrm{~kJ} / 100 \mathrm{~g}$ and a macronutrient composition of $56 \mathrm{E} \%$ carbohydrate, $27 \mathrm{E} \%$ fat and $17 \mathrm{E} \%$ protein. The subjects were instructed to eat until comfortably satiated. The ad libitum test meal has previously been shown to be a reproducible method to measure spontaneous $\mathrm{EI}^{(26)}$.

\section{Questionnaires}

A $100 \mathrm{~mm}$ visual analogue scale was used to determine changes in subjective appetite sensations during the test day, and completed every half hour between 09.00 and 14.30 hours. Specific scales were as follows: satiety; hunger; fullness; prospective food consumption; thirst; well-being; desire to eat something fatty, sweet, salty and savoury. The use, reproducibility and validity of the VAS have been described in a previous report from this laboratory ${ }^{(27)}$.

The VAS used for subjective evaluation of the visual appeal, smell, taste, aftertaste and overall palatability of the test meals were filled out after the consumption of the test meals. For visual appeal, smell, taste and overall palatability, a low score corresponds to the rating 'good', whereas a high score equals the rating 'bad'. With regard to aftertaste, a low score is associated with 'much' aftertaste, whereas a high score is associated with 'none'.

\section{Urine collection}

The subjects collected their urine between 08.00 and 14.00 hours in pre-weighed airtight containers. The volume and density of the collected urine was determined and three samples were drawn and stored at $-20^{\circ} \mathrm{C}$ until further analysis. These samples were later analysed for levels of $\mathrm{N}$, adrenaline and noradrenaline.

\section{Data}

DIT $(\mathrm{kJ} / \mathrm{h})$ was calculated as the incremental area under the curve for resting EE after the test meal with RMR used as the baseline measure.

Since the design of the study did not allow for calculation of a normal $24 \mathrm{~h}$-based energy balance, we calculated an estimate of the energy balance using the following equation:

Energy balance $=\mathrm{EI}_{\text {test meal }}+\mathrm{EI}_{\text {ad libitum meal }}-\mathrm{EE}_{\text {4h period }}$.

Table 2. Energy content and macronutrient composition of the test meal for the five treatments $(n$ 22)

\begin{tabular}{lccccc}
\hline Treatment & Ginger & Horseradish & Mustard & Placebo & Black pepper \\
\hline Energy content (kJ) & 2907 & 2883 & 2954 & 2846 & 2867 \\
Carbohydrate (E\%) & 60 & 59.7 & 59.6 & 59.6 & 59.6 \\
Fat (E\%) & 26.1 & 26.2 & 26.4 & 26.5 & 26.5 \\
Protein (E\%) & 13.9 & 14.1 & 14 & 13.9 & 13.9 \\
\hline
\end{tabular}

$\mathrm{E} \%$, percentage of energy. 


\section{Statistical analyses}

Calculations of sample size were based on data from previous studies on other bioactive ingredients conducted at this laboratory, which are designed to identify a change of $2 \%$ in $24 \mathrm{~h}$ thermogenesis with a power of $0 \cdot 8$.

Data were analysed by mixed-model ANCOVA. The parameters DIT, RQ, fat and carbohydrate oxidation, ad libitum energy intake, HR, and systolic and diastolic BP were evaluated separately in univariate analyses. Treatment, previous treatment, hood, period (visit number) and interaction between treatment and period were included in the analyses as categorical explanatory variables. Age, body weight, fatfree mass and fat mass were also included in the analyses as covariates and, finally, subject-specific random effects were included to account for inter-subject variability and to adjust for any non-specific differences not captured by the explanatory variables included in the analyses. When the main effect of treatment was significant, post hoc comparisons were made using $t$ tests with the Tukey-Kramer adjustment of $P$ values.

Furthermore, repeated-measures ANCOVA were performed to examine differences in time within periods. In these models, subjects were nested within periods.

The catecholamine data were analysed by ANCOVA with $6 \mathrm{~h}$ adrenaline and noradrenaline levels as independent variables. Treatment, previous treatment, period and interaction between treatment and period were included as categorical explanatory variables, whereas age and body weight were included as covariates. Subject-specific random effects were also included.

VAS scores for appetite-related measures were analysed as repeated measures using a mixed-model ANCOVA. Whenever the main effect of treatment was significant, post boc comparisons were based on $t$ tests with the Tukey-Kramer adjustment of $P$ values. Again, treatment, previous treatment, period and interaction between treatment and period were included as categorical explanatory variables, and age and body weight as covariates, and subjects as a dependent random variable. Subject-specific random effects were also included.

For all statistical models, residuals were examined for normality by histograms and Shapiro-Wilk's tests, and variance homogeneity was assessed by means of residual plots. All results are presented as means with their standard errors or standard deviations. The significance level was set at $P<0 \cdot 05$. Statistical analyses were performed using SAS 9.1 (SAS Institute).

\section{Results}

Of the twenty-five subjects, two dropped out of the study during their first and second visit, respectively, due to back problems. The subjects reported that their back problems were present before entering the study and thus not caused by the study procedures. A third subject dropped out after the first visit because he disliked some of the food items of the test meal. Thus, twenty-two subjects completed the study and their physical characteristics are shown in Table 1.

\section{Evaluation of the test brunch meal}

We observed no difference between the test brunch meals with regard to visual appeal (range 34.6 (SE 4.1) to 43.6 (SE 5.7) mm, $P=0.22$ ) and smell (range 35.9 (SE 3.4) to 46.7 (SE 4.0$) \mathrm{mm}$, $P=0 \cdot 19$ ), but a tendency towards a treatment effect on the overall palatability of the test meal $(P=0.08)$, with the placebo meal being more palatable than the horseradish meal according to post hoc analyses $(37 \cdot 5$ (SE 4.5) v. 47.3 (SE 6.1) mm, respectively, $P=0 \cdot 04)$. However, there was a significant treatment effect on the taste of the test meals $(P<0 \cdot 0003)$ with post hoc analyses showing the ginger and horseradish meals to be rated less liked than placebo $(48.7(\mathrm{SE} 5.6) v .28 .5(\mathrm{SE} \mathrm{3.7)} \mathrm{mm}, P=0.02$ and $58.4(\operatorname{se~5.8)~v.~} 28.5(\operatorname{se~3.7)~} \mathrm{mm}, P<0.0001$, respectively), and tendencies for the mustard and black pepper meals to be better tasting than the horseradish meal (41.4 (SE 5.1) v. 58.4 (sE 5.8) $\mathrm{mm}, P=0.07$ and 40.5 (SE 4.9) v. 58.4 (SE 5.8) $\mathrm{mm}$, $P=0 \cdot 050$, respectively). Finally, there was a significant treatment effect on the aftertaste following the test meal $(P<0 \cdot 0001)$. Post hoc analyses showed that all spiced meals were rated as having more aftertaste than the placebo test meal (range: spicy meals $19 \cdot 3$ (SE 5.3) to 49.5 (SE 6.7) $\mathrm{mm} v$. placebo 84.0 (se 3.2 ) $\mathrm{mm}, P<0.001$ ), and that the aftertaste was larger following horseradish compared with both the mustard (19.3 (se 5.3) v. $49.5($ se 6.7$) \mathrm{mm}, P=0.002)$ and black pepper (19.3 (se 5.3) v. $45 \cdot 0(6 \cdot 2) \mathrm{mm}, P=0 \cdot 01)$ meals.

\section{Diet-induced thermogenesis}

The main statistical analysis showed a treatment effect on DIT $(P=0.0004)$. Post hoc analyses showed that mustard (59 (sE 3) kJ/h) increased DIT compared with ginger (46 (sE 2) kJ/h, $P=0.0003$ ), horseradish ( $48($ SE 2$) \mathrm{kJ} / \mathrm{h}, P=0.004)$ and black pepper (49 (sE 3) kJ/h, $P=0.02$ ), and also tended to increase DIT compared with placebo (52 (sE 2$) \mathrm{kJ} / \mathrm{h}, P=0 \cdot 08$ ) (Fig. 1).

\section{Respiratory quotient and substrate oxidation}

There were no significant effects of the treatments on RQ $(P=0.73)$, fat or carbohydrate oxidation $(P=0.17$ and $P=0.31$, respectively).

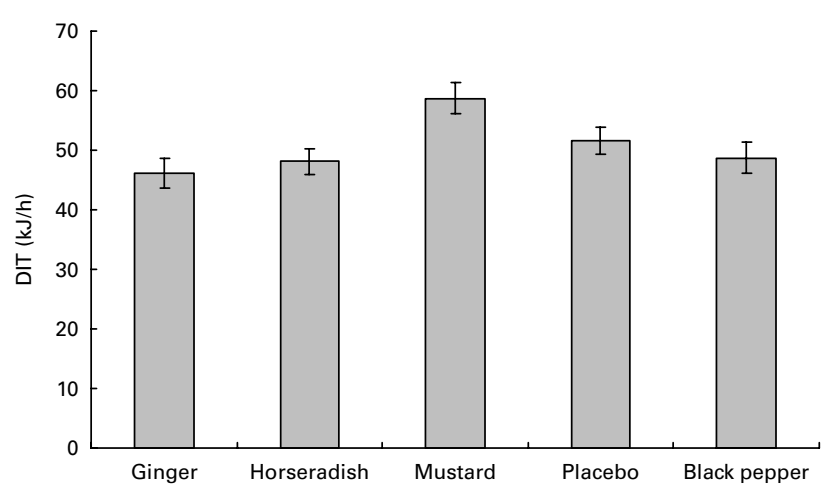

Fig. 1. Diet-induced thermogenesis (DIT; kJ/h; calculated as the incremental area under the curve) in twenty-two healthy, normal-weight young males after treatment with ginger, horseradish, mustard, placebo and black pepper. Values are means, with their standard errors represented by vertical bars. The repeated-measures statistical analyses (Tukey-Kramer) showed significant differences between mustard and the three other active treatments $(P<0.023)$ and a similar tendency of mustard towards placebo $(P=0.083)$. 


\section{Catecholamines}

We observed no significant effects of the treatments on levels of adrenaline $(P=0.50)$ or noradrenaline $(P=0.71)$. For the analysis on the adrenaline data, fat-free mass $(P=0.04)$, BMI $(P=0.03)$ and visit $(P=0.049)$ were significant covariates.

\section{Haemodynamic factors}

There was a significant treatment effect on diastolic BP $(P=0.001$; Fig. 2). Post hoc analyses revealed that horseradish increased diastolic BP compared with placebo $(0.4 \mathrm{mmHg}$ (baseline adjusted), $P=0.049)$, black pepper (1.9 $\mathrm{mmHg}$ (baseline adjusted), $P<0.0001)$ and ginger $(1.4 \mathrm{mmHg}$ (baseline adjusted), $P=0.050)$. No other differences between the treatments were observed. Time $(P<0 \cdot 0001)$, baseline levels $(P<0.0001)$, visit $(P<0.0001)$ and previous treatment $(P=0.005)$ were significant covariates. No effects of the treatments were seen on systolic BP $(P=0 \cdot 15)$.

Finally, we observed a significant treatment effect on HR $(P=0.007)$, with post hoc analyses showing a decreased HR following horseradish compared with both mustard and placebo (baseline-adjusted values: 0.4 and 0.8 beats $/ \mathrm{min}$, respectively, $P=0.048$ ) (Fig. 3). As expected, the baseline levels of $\mathrm{HR}$ $(P<0.0001)$ and time $(P<0.0001)$ were significant covariates. Surprisingly, BMI $(P=0 \cdot 002)$, visit $(P=0 \cdot 004)$ and previous treatment $(P=0.003)$ were also significant covariates.

\section{Ad libitum energy intake}

There were no treatment effects on ad libitum EI $(P=0.62)$. Ad libitum EI was insignificantly decreased by $2.6 \%$ ( $-152 \mathrm{~kJ} v$. placebo) following the mustard treatment $(5557$ (SE 335) kJ) compared with placebo (5709 (SE 281) kJ). Smaller

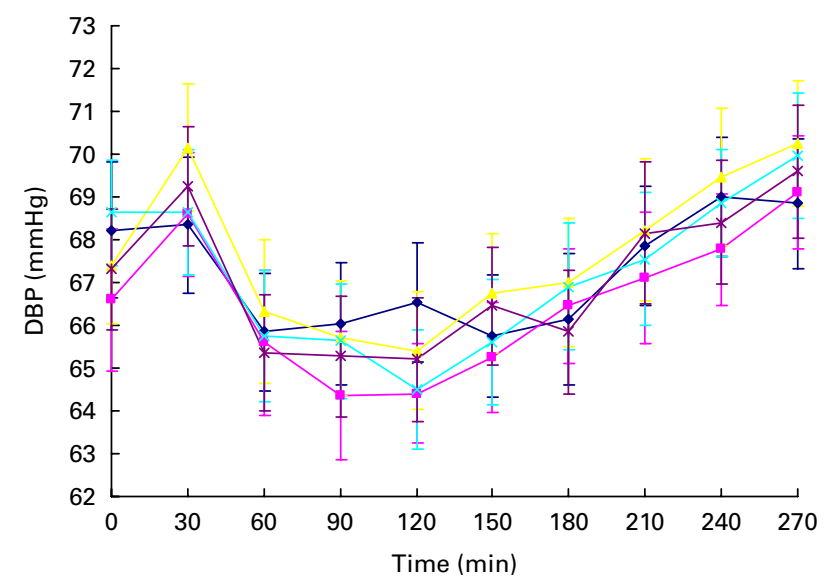

Fig. 2. Diastolic blood pressure (DBP) in twenty-two healthy, normal-weight young males after treatment with ginger $(-)$, horseradish $(-)$, mustard $(*)$, placebo (-) and black pepper $(\rightarrow)$. Values are means for each of the treatments before the test meal (served at $0 \mathrm{~min}$ ) and during the postprandial period $(0-270 \mathrm{~min})$, with their standard errors represented by vertical bars. Repeatedmeasures statistical analyses (Tukey-Kramer) showed that horseradish increased DBP compared with placebo and black pepper $(P<0.05)$ and a similar tendency towards ginger $(P=0.05)$, but not mustard $(P=0.22)$. (A colour version of this figure can be found online at http://www.journals.cambridge.org/bjn)

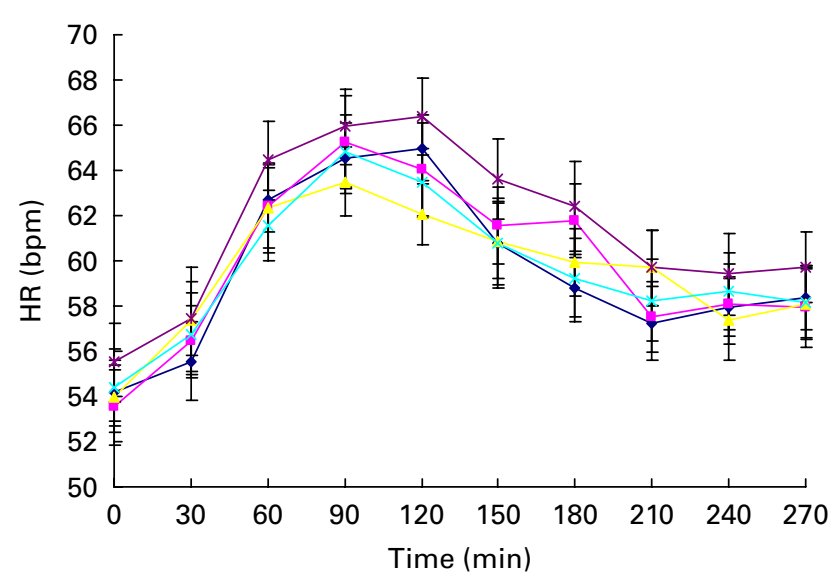

Fig. 3. Heart rate $(\mathrm{HR})$ in twenty-two healthy, normal-weight young males after treatment with ginger $(-)$, horseradish $(-)$, mustard $(*)$, placebo $(-)$ and black pepper $(*)$. Values are means for each of the treatments before the test meal (served at $0 \mathrm{~min}$ ) and during the postprandial period (0-270 min), with their standard errors represented by vertical bars. Repeated-measures statistical analyses (Tukey-Kramer) showed that horseradish decreased $\mathrm{HR}$ compared with mustard and placebo $(P<0.049)$, but not ginger and black pepper $(P>0.96)$. bpm, beats per min. (A colour version of this figure can be found online at http://www.journals.cambridge.org/bjn)

non-significant differences from placebo intake were seen for the remaining treatments: ginger $(5672(\mathrm{sE} 378) \mathrm{kJ})$, horseradish (5616 (sE 320) kJ) and black pepper (5835 (sE 375) kJ).

\section{Appetite measures}

There were no treatment effects on the VAS scores for satiety ( $P=0.86)$, hunger $(P=0.90)$, fullness $(P=0.97)$ and prospective food intake $(P=0.90)$. Likewise, no effects of the treatments were observed on measures of well-being $(P=0.42)$, thirst ( $P=0.24)$, and desires for something sweet $(P=0.69)$, salty $(P=0.85)$, fatty $(P=0.68)$ or savoury $(P=0.54)$.

\section{Energy balance}

Post hoc analyses showed no differences between the treatments in energy balance $(P=0.67)$.

\section{Blood parameters}

Of the analysed blood parameters, significant treatment effects were only observed for HDL levels $(P=0 \cdot 0002)$. Post boc analyses showed that black pepper significantly decreased HDL levels compared with both placebo $(P=0.03)$ and horseradish $(P<0 \cdot 0001)$. Additionally, black pepper also tended to decrease HDL levels compared with mustard $(P=0.059)$ and ginger $(P=0 \cdot 07)$.

\section{Discussion}

Overall, none of these spices significantly affected measures of EE, substrate utilisation or appetite relative to the control meal. Only the addition of mustard to a test meal tended to increase DIT compared with placebo. The absolute increase in DIT for mustard $v$. placebo (approximately $7 \mathrm{~kJ} / \mathrm{h}$ over $4 \mathrm{~h}$ ) was very 
small, but could make a contribution towards that which could be meaningful on a population basis, though much more so if the effect could be further enhanced in a single meal, or extrapolated to $90-100 \mathrm{~kJ} / \mathrm{d}$ from three meals.

Minor differences in the energy contents of the test meals (Table 2) may have had small effects on the results, although they are unlikely to explain the entire variation in their thermogenic effects. Based on the thermic effect of macronutrients ${ }^{(28)}$, differences in the DIT of the test meals would be no more than about $7-13 \mathrm{~kJ}$. Furthermore, for the placebo and mustard meals specifically, the energy content of the latter was greater by a factor of $1.04(2954 / 2846 \mathrm{~kJ})$, whereas DIT was increased by a factor of $1 \cdot 14(59 / 52 \mathrm{~kJ} / \mathrm{h})$. Lastly, spices may affect thermogenesis through relatively rapid mechanisms $(2-4 \mathrm{~h})^{(3,4,21)}$, whereas the macronutrients have been shown to affect DIT up to $8 \mathrm{~h}$ postprandially ${ }^{(28-30)}$. This suggests that any thermic effect of the spices would most probably have been captured by our measuring period, whereas the entire macronutrientinduced DIT may not have been.

The present study indicates little thermogenic effects of the test spices at these levels. However, this is the first report of a potential effect of mustard per se on DIT in human subjects, though the results are only indicative and need to be confirmed. Henry \& Emery ${ }^{(21)}$ previously described a significant effect of a chilli-mustard sauce on RMR. They reported an increase in RMR of $153(\mathrm{SE} 8) v .128(\mathrm{SE} 7) \%$ for the spiced $v$. non-spiced meal, and the metabolic rate for both meals reached a maximum at about $75-90$ min postprandially ${ }^{(21)}$. Unfortunately, their study design does not allow separation of the effects of mustard and chilli, nor quantification of the actual effect, since RMR was reported as a percentage of fasting $\mathrm{RMR}^{(21)}$. It would have been of value to be able to separate these effects, since Simons et al. ${ }^{(31)}$ have shown cross-desensitisation between mustard oil and capsaicin, suggesting potential inter-inhibition between these components.

To our knowledge, only one other human study has investigated the effects of mustard (or AITC) alone on thermogenesis, but this study showed no effect ${ }^{(20)}$. A few studies have shown that AITC can activate different thermosensitive transient receptor potential channels, especially TRPA1 and TRPV1 $1^{(23,32,33)}$. This could potentially support an SNS-activated effect of mustard on EE (and EI) similar to the corresponding effect of capsaicin. The important role of the SNS for the effects of bioactive components from spices has been shown in a number of studies $^{(4,15,16,21)}$.

The effect size seen in the present study seems too small to be relevant at this dose of mustard, even if summed up to an entire day (e.g. three meals). If the level of whole spice cannot be increased without discomfort and/or side effects, an alternative approach could be to isolate the active ingredient(s) and combine this with other effective active components, or technical routes to mask the pungency. A combination approach could be interesting, especially if synergistic effects are present. Previously, Belza et al. ${ }^{(34)}$ has suggested synergistic effects between different bioactive components, including capsaicin and catechins. However, since the present study investigated the effects of mustard in the context of real food, it should be examined whether AITC is its only active ingredient affecting components of energy balance. Subsequently, the mechanisms behind these effects should be elucidated, before examining possibilities of enhanced effects from combining the active ingredient(s) from mustard with other active ingredients. Knowledge of the effect size and variance from the present study can be used to better calculate and therefore improve the power of further studies, and thus evaluate the robustness of the (small) effect observed here.

The fact that none of the spices other than mustard showed any evidence at all of potential thermogenic effects was somewhat unexpected. Data from rats show increased catecholamine levels following infusion with zingerone and piperine, but not AITC $^{(15)}$. Given the observed effect of mustard, the lack of the effect of horseradish may seem surprising, as these (and wasabi) share the pungent component AITC ${ }^{(23)}$. However, since we used the spices in the context of real food, they were not standardised for putative active compounds, and the content of AITC in mustard may have been larger than in horseradish. This again calls for studies to isolate and standardise the relevant active component(s) in mustard or other spices used in testing.

Another potential explanation for the lack of the effects of the tested pungent spices on thermogenesis could be that the subjects may have been habitual consumers of spicy foods and thereby have been desensitised to the effects of these as shown by Ludy \& Mattes ${ }^{(35)}$. However, since we did not record the frequency of the use of pungent foods for the subjects, we cannot be sure that this was the case for our subjects.

The tendency of mustard to increase DIT was not accompanied by an increase in BP or HR, nor did mustard (or any other spice) cause changes in catecholamine levels. Nonetheless, horseradish increased diastolic BP, but at the same time decreased HR, which seems to be inconsistent. To our knowledge, no other human studies have examined the effects of horseradish (or the other examined spices) on these endpoints, but previous studies have shown that an effect of capsaicin on thermogenesis mediated via the SNS can produce a concomitant increase in $\mathrm{BP}$ and $\mathrm{HR}^{(36,37)}$. However, a recent study in genetically hypertensive rats showed that chronic activation of TRPV1 receptors (by capsaicin) through a cascade of events resulted in lowered $\mathrm{BP}^{(38)}$. Thus, our understanding of these potential effects and mechanisms is still limited.

Alternatively, the effect size may simply have been too small, or the effect of mustard may not be the result of a SNS-related mechanism, a view supported by a study in rats showing no effects of AITC on catecholamine secretion ${ }^{(15)}$. Use of a pharmacological SNS-blocking agent (e.g. the $\beta$-adrenergic antagonist propranolol) could help clarify this ${ }^{(13)}$.

The lack of differences between the treatments with regard to $\mathrm{RQ}$, fat and carbohydrate oxidation is consistent with the small effects on DIT. However, a recent study showed that intragastric administration of AITC increased carbohydrate oxidation in mice through TRPV1 receptors ${ }^{(39)}$. Nevertheless, the evidence in this area is still very sparse.

We found no effect of the spices on subjective appetite measures or ad libitum EI. However, the ad libitum EI was non-significantly lower (150 kJ, approximately 3\%) following the mustard meal $v$, the placebo meal. Whether this difference 
is reliable should be examined in future studies. The present study was not designed with ad libitum EI as the main outcome, and thus the time period between the test meal and the ad libitum lunch has most probably been too long $(4.5 \mathrm{~h})$. Therefore, we would recommend a shorter interval between such meals in future studies if the aim is to pick up potential effects on ad libitum EI. One way of doing this would be to serve the test meal as a preload shortly before the ad libitum meal. The effects of the tested spices on appetite and ad libitum EI have been examined by two other studies. Reinbach et al. ${ }^{(40)}$ showed that ginger decreased the ad libitum EI, whereas no effects were seen for mustard, chilli, horseradish or wasabi, respectively. Only wasabi increased prospective food consumption $^{(40)}$. Finally, a study by Wu et al. ${ }^{(41)}$ showed no effect of ginger on fullness or desire to eat.

Despite the effort put into making the meals equally and highly palatable, the horseradish meal was still rated as being less tasty and palatable than the placebo meal. Likewise, the ginger meal was also rated as less tasty compared with placebo. However, since we observed no treatment differences in subsequent appetite ratings or ad libitum EI, the impact of these differences seems to have been negligible.

Interestingly, due to large variation, the numerical reduction in an ad libitum EI of approximately $150 \mathrm{~kJ}$ on mustard $v$. placebo was clearly non-significant, whereas the tendency towards a difference in a DIT of approximately $30 \mathrm{~kJ}$ during the $4 \mathrm{~h}$ was not. Looking at these together in a post hoc analysis of energy balance showed no significant differences between the treatments. Again, this result could potentially have turned out differently if the study had been designed to be more sensitive towards picking up changes in EI. Future studies may benefit from focusing primarily on energy balance (thus EE + EI effects together) and therefore also basing the power calculations on this in order to increase the likelihood of picking up potentially relevant differences around this size $(180 \mathrm{~kJ})$ as statistically significant.

The fact that black pepper had HDL-lowering effects could be a side effect of this spice. In one study in rats that examined the effects of long-term (10 weeks) administration of piperine on plasma lipid levels, increased HDL levels and decreased levels of other plasma lipids were found when administered together with a high-fat diet ${ }^{(42)}$. Thus, the effects of piperine on plasma lipid levels may depend on the combination and amounts of macronutrients that are served concomitantly and therefore also needs further investigation.

\section{Conclusion}

At palatable levels in food, none of the spices tested here had statistically significant effects on any of the primary or secondary outcome measures relating to energy metabolism, appetite or food intake. Mustard tended to be thermogenic at this dose without adverse effects; however, the effect size was small, and more studies with slightly modified designs are needed to establish the robustness of the possible effects of mustard on DIT (and EI), and whether these could be enhanced at higher doses or novel combinations with other active agents. The present study will be greatly facilitated by improved knowledge of the mechanisms involved and standardisation of the putative bioactive component(s). Likewise, the long-term effects of small but sustained increases in EE due to mustard or other agents merit further study.

\section{Acknowledgements}

This study was funded by the Programme Commission on Health, Food and Welfare (the Danish Council for Strategic Research). N. T. G. was supported by a research grant from Unilever and D. J. M. is employed by Unilever, a company that works with food components. None of the authors had any conflict of interest to declare. The authors would like to thank Jane Jørgensen, Inge Timmermann, Susanne Korsholm, Søren Andresen, Charlotte Kostecki, Yvonne Fatum, Karina Graff Rossen and John Lind for expert technical assistance. A. B., C. B. and A. A. planned the study, and A. B. and C. B. wrote the protocol. N. T. G. and M. G. J. conducted the study. N. T. G. analysed the data with help from C. R., O. H., A. B., E. F., D. J. M. and A. A. N. T. G. wrote the manuscript and the rest of the authors reviewed the manuscript.

\section{References}

1. World Health Organization (2008) Programmes and Projects. Media Centre. Fact Sheet no. 311. Version September 2006. http://www.who.int/mediacentre/factsheets/fs311/en/index. html (accessed June 2008).

2. Wing RR \& Phelan S (2005) Long-term weight loss maintenance. Am J Clin Nutr 82, 222S-225S.

3. Yoshioka M, St-Pierre S, Suzuki M, et al. (1998) Effects of red pepper added to high-fat and high-carbohydrate meals on energy metabolism and substrate utilization in Japanese women. Br J Nutr 80, 503-510.

4. Yoshioka M, Lim K, Kikuzato S, et al. (1995) Effects of redpepper diet on the energy metabolism in men. J Nutr Sci Vitaminol 41, 647-656.

5. Dulloo AG, Duret C, Rohrer D, et al. (1999) Efficacy of a green tea extract rich in catechin polyphenols and caffeine in increasing 24-h energy expenditure and fat oxidation in humans. Am J Clin Nutr 70, 1040-1045.

6. Berube-Parent S, Pelletier C, Dore J, et al. (2005) Effects of encapsulated green tea and Guarana extracts containing a mixture of epigallocatechin-3-gallate and caffeine on $24 \mathrm{~h}$ energy expenditure and fat oxidation in men. Br J Nutr 94, 432-436.

7. Yoshioka M, Saint-Pierre S, Drapeau V, et al. (1999) Effects of red pepper on appetite and energy intake. Br J Nutr $\mathbf{8 2}$, 115-123.

8. Yoshioka M, Doucet E, Drapeau V, et al. (2001) Combined effects of red pepper and caffeine consumption on $24 \mathrm{~h}$ energy balance in subjects given free access to foods. $\mathrm{BrJ}$ Nutr 85, 203-211.

9. Lejeune MP, Kovacs EM \& Westerterp-Plantenga MS (2003) Effect of capsaicin on substrate oxidation and weight maintenance after modest body-weight loss in human subjects. Br J Nutr 90, 651-659.

10. Westerterp-Plantenga MS, Smeets A \& Lejeune MP (2005) Sensory and gastrointestinal satiety effects of capsaicin on food intake. Int J Obes 29, 682-688.

11. Kawada T, Hagihara K \& Iwai K (1986) Effects of capsaicin on lipid metabolism in rats fed a high fat diet. J Nutr 116, 1272-1278. 
12. Matsuo T, Yoshioka M \& Suzuki M (1996) Capsaicin in diet does not affect glycogen contents in the liver and skeletal muscle of rats before and after exercise. J Nutr Sci Vitaminol 42, 249-256.

13. Belza A, Gille MB, John SS, et al. (2009) The beta-adrenergic antagonist propranolol partly abolishes thermogenic response to bioactive food ingredients. Metabolism 58, $1137-1144$.

14. Smeets A \& Westerterp-Plantenga M (2009) The acute effects of a lunch containing capsaicin on energy and substrate utilization, hormones, and satiety. Eur J Nutr 48, 229-234.

15. Kawada T, Sakabe S, Watanabe T, et al. (1988) Some pungent principles of spices cause the adrenal medulla to secrete catecholamine in anesthetized rats. Proc Soc Exp Biol Med 188, 229-233.

16. Watanabe T, Kawada T, Kurosawa M, et al. (1988) Adrenal sympathetic efferent nerve and catecholamine secretion excitation caused by capsaicin in rats. Am J Physiol 255, E23-E27.

17. Kawada T, Watanabe T, Takaishi T, et al. (1986) Capsaicininduced beta-adrenergic action on energy metabolism in rats: influence of capsaicin on oxygen consumption, the respiratory quotient, and substrate utilization. Proc Soc Exp Biol Med 183, 250-256.

18. Clapham DE (2009) Some like it hot: spicing up ion channels. Nature 389, 783-784.

19. Iwasaki $\mathrm{Y}$, Morita A, Iwasawa T, et al. (2006) A nonpungent component of steamed ginger-[10]-shogaol increases adrenaline secretion via the activation of TRPV1. Nutr Neurosci 9, 169-178.

20. Henry CJ (1987) Effect on ginger on metabolic rate. Hum Nutr Clin Nutr 41, 89-92.

21. Henry CJ \& Emery B (1986) Effect of spiced food on metabolic rate. Hum Nutr Clin Nutr 40, 165-168.

22. McNamara FN, Randall A \& Gunthorpe MJ (2005) Effects of piperine, the pungent component of black pepper, at the human vanilloid receptor (TRPV1). Br J Pharmacol 144, 781-790.

23. Ohta T, Imagawa T \& Ito S (2007) Novel agonistic action of mustard oil on recombinant and endogenous porcine transient receptor potential V1 (pTRPV1) channels. Biochem Pharmacol 73, 1646-1656.

24. Elia M \& Livesey G (1992) Energy expenditure and fuel selection in biological systems: the theory and practice of calculations based on indirect calorimetry and tracer methods. World Rev Nutr Diet 70, 68-131.

25. Friedewald WT, Levy RI \& Fredrickson DS (1972) Estimation of the concentration of low-density lipoprotein cholesterol in plasma, without use of preparative ultracentrifuge. Clin Chem 18, 499-502.

26. Gregersen NT, Flint A, Bitz C, et al. (2008) Reproducibility and power of ad libitum energy intake assessed by repeated single meals. Am J Clin Nutr 87, 1277-1281.
27. Flint A, Raben A, Blundell J, et al. (2000) Reproducibility, power and validity of visual analogue scales in assessment of appetite sensations in single test meal studies. Int J Obes 24, 38-48.

28. Tappy L (1996) Thermic effect of food and sympathetic nervous system activity in humans. Reprod Nutr Dev 36, 391-397.

29. D'Alessio DA, Kavle EC, Mozzoli MA, et al. (1988) Thermic effect of food in lean and obese men. J Clin Invest $\mathbf{8 1}$, 1781-1789.

30. Westerterp K (2004) Diet induced thermogenesis. Nutr Metab 1, 5 .

31. Simons CT, Carstens MI \& Carstens E (2003) Oral irritation by mustard oil: self-desensitization and cross-desensitization with capsaicin. Chem Senses 28, 459-465.

32. Jordt SE, Bautista DM, Chuang HH, et al. (2004) Mustard oils and cannabinoids excite sensory nerve fibres through the TRP channel ANKTM1. Nature 427, 260-265.

33. Iwasaki Y, Tanabe M, Kobata K, et al. (2008) TRPA1 agonists - allyl isothiocyanate and cinnamaldehyde - induce adrenaline secretion. Biosci Biotechnol Biochem 72, 2608-2614.

34. Belza A, Frandsen E \& Kondrup J (2006) Body fat loss achieved by stimulation of thermogenesis by a combination of bioactive food ingredients: a placebo-controlled, doubleblind 8-week intervention in obese subjects. Int J Obes $\mathbf{3 1}$, 121-130.

35. Ludy MJ \& Mattes RD (2011) The effects of hedonically acceptable red pepper doses on thermogenesis and appetite. Physiol Behav 102, 251-258.

36. Hachiya S, Kawabata F, Ohnuki K, et al. (2007) Effects of CH-19 sweet, a non-pungent cultivar of red pepper, on sympathetic nervous activity, body temperature, heart rate, and blood pressure in humans. Biosci Biotechnol Biochem 71, 671-676.

37. Osaka T, Kobayashi A, Lee TH, et al. (2000) Lack of integrative control of heat production and heat loss after capsaicin administration. Pflugers Arch 440, 440-445.

38. Yang D, Luo Z, Ma S, et al. (2010) Activation of TRPV1 by dietary capsaicin improves endothelium-dependent vasorelaxation and prevents hypertension. Cell Metab 12, 130-141.

39. Mori N, Kawabata F, Matsumura S, et al. (2011) Intragastric administration of allyl isothiocyanate increases carbohydrate oxidation via TRPV1 but not TRPA1 in mice. Am J Physiol Regul Integr Comp Physiol 300, R1494-R1505.

40. Reinbach HC, Martinussen T \& Møller P (2010) Effects of hot spices on energy intake, appetite and sensory specific desires in humans. Food Qual Prefer 21, 655-661.

41. Wu KL, Rayner CK, Chuah SK, et al. (2008) Effects of ginger on gastric emptying and motility in healthy humans. Eur J Gastroenterol Hepatol 20, 436-440.

42. Vijayakumar RS \& Nalini N (2006) Piperine, an active principle from Piper nigrum, modulates hormonal and apo lipoprotein profiles in hyperlipidemic rats. J Basic Clin Physiol Pharmacol 17, 71-86. 